\title{
EFFICACY OF COMMERCIAL ATTRACTIVE TOXIC SUGAR BAIT STATION (ATSB) AGAINST AEDES ALBOPICTUS
}

\author{
VINDHYA S. ARYAPREMA, EDWARD ZESZUTKO, \\ COURTNEY CUNNINGHAM, EMAD I. M. KHATER AND RUI-DE XUE \\ Anastasia Mosquito Control District, 120 EOC Drive, \\ St. Augustine, FL, USA
}

Guest Editor: Gunter C. Muller

\begin{abstract}
The use of toxic sugar baits is a new paradigm in mosquito control. A commercial product of attractive toxic sugar bait station (Spartan Mosquito Eradicator) contains a toxic sugar bait with sodium chloride as the active ingredient and yeast as an attractant. We studied the efficacy of the device against adult Aedes albopictus Skuse. The study composed of a laboratory and a field component with treatment and control cohorts. The treatment in the laboratory experiment resulted in nonsignificant mortality of adult mosquitoes compared with untreated mosquitoes. Neither laboratory nor field components of the study showed significant evidence that the commercial product could reduce the abundance of Ae. albopictus in the natural environment. The device may need to be improved and further evaluation conducted.
\end{abstract}

Key Words: attractive toxic sugar bait, Aedes albopictus, sodium chloride, efficacy

The use of toxic sugar baits (TSB) targeting sugar feeding behavior of the mosquito is an expanding technology in the field of mosquito control (Fiorenzano et al. 2017). Lea, in 1965 pioneered the method with malathion in a sucrose solution formulating the first mosquito toxic sugar bait (TSB) which was fed to Aedes aegypti (Lea 1965). Since then, different toxic substances including boric acid (Blore et al 2018, Qualls et al. 2015, Xue et al. 2006, Xue \& Barnard 2003), eugenol (Qualls et al 2014), chlorfenapyr and tolfenpyrad (Stewart et al. 2013) and ivermectin (Maia et al. 2018) have been evaluated against a number of adult mosquito vectors. Adult mosquitoes have easy access to sugar sources, like floral and extra floral nectaries, rotted fruits and damaged fruits in the environment (Bidlingmayer 1973, Foster 1995). Toxic sugar baits have thus been supplemented with suitable attractants that attract adult mosquitoes for the bait in spite of the availability of natural sugars (Qualls et al. 2014). Since the control of mosquito populations with traditional insecticides are becoming less effective due to the development of resistance (Deming et al. 2016), the ATSBs may be an important alternative option. New ATSB products are therefore, considered to be introduced to the market.

Spartan Mosquito Eradicator is a device with an ATSB released to the market targeting control of adult mosquito populations. The commercial device is a plastic tube $(5 \mathrm{~cm} \mathrm{D} \times 27 \mathrm{~cm} \mathrm{H})$ containing a product of $11.48 \%$ sodium chloride (active ingredientthe toxic substance), $0.18 \%$ yeast (the attractant) and $88.34 \%$ sucrose as a dry powder indicated on the label. The tube lid has 6 small holes of $\sim 3 \mathrm{~mm}$ diameter through which the mosquitoes are supposed to go in and feed on the dissolved product. It is designed to hang on trees or structures in the environment. The purpose of this study was to evaluate the effectiveness of the commercial product in reducing population densities of Aedes albopictus (Skuse,1894), an important vector of arboviral diseases, such as dengue, zika and chikungunya (Kumari et al. 2011, McKenzie et al. 2019, Monteiro et al. 2019, Paupy et al. 2012, Sivan et al. 2016) that is geographically well distributed over the globe (Kraemer et al. 2015, Paupy et al. 2009).

The study was carried out from October to December 2019 in the laboratory and 
field. The commercial products were purchased from online and shipped to AMCD by BioOpus LLC for evaluation. The laboratory study was carried out in three mosquito bug-dorms (BugDorm-2120 insect rearing tent, MegaView Science Co., Ltd. Taiwan) each containing 5-7 day old, 100 female and 100 male Ae. albopictus obtained from the insectary of the Anastasia Mosquito Control District (AMCD). One bug-dorm was provided with a Spartan Mosquito Eradicator tube with the original product dissolved in water (treatment bug-dorm) as per the manufacturer's guidelines to make a solution of $450 \mathrm{ml}$. Once dissolved the actual proportion of active ingredient in the solution was $1 \%$ and the proportion of sucrose was $8 \%$. The control bug-dorm was thus provided with a Spartan Mosquito Eradicator tube containing only $8 \%$ sucrose solution and the other bug-dorm was provided with two Spartan Mosquito Eradicator tubes, one with the dissolved product and the other with $8 \%$ sucrose solution to give the mosquitoes a choice (choice bug-dorm). Number of dead mosquitos in each bug-dorm (in both the tube and the dorm) was counted at $24 \mathrm{~h}$ intervals for 72 hours. Temperature and relative humidity $(\mathrm{RH})$ of the three laboratory replicates ranged from $18.2{ }^{\circ} \mathrm{C}-24.6{ }^{\circ} \mathrm{C}$ and RH: $56.1 \%-63.9 \%$ respectively.
The field study was carried out at two locations with large tire piles which are known to have high abundance of Ae. albopictus. One location was used as the control site and the other as the treatment site rotating bi-weekly to minimize any bias characterized to the location. Five tubes were placed at each site, the distance between each tube was 4 meters; the tubes at the control site had the $8 \%$ sucrose solution only and the tubes at the treatment site had the dissolved Spartan product. Weekly mortality counts in each tube were recorded. One BG Sentinel trap (without $\mathrm{CO}_{2}$ ) was set out weekly at each site for 24 hours and collected mosquitoes were identified and counted. The study was carried out for 8 weeks.

Notable control mortalities, mainly in males, were observed for all laboratory replicates in spite of all possible remedial measures (Figure 1). Most of the dead mosquitoes were found in the bug-dorm and comparatively very few inside the tubes. It indicates that the mosquitoes were dying due to deprivation of water/sugar (desiccating) as they were not able to enter the devices through the very small holes. Comparatively low female mortality (Figure 1) was likely due to the generally higher survival fitness of females. Mortalities in both males and females were lower in choice bug-dorms than in control bug-dorms (Figure 1). Each preferential bug-dorm having two



$\square 24 \mathrm{~h} \square 48 \mathrm{~h} \square 72 \mathrm{~h}$

Figure 1. Cumulative mortality of Aedes albopictus exposed to Spartan Mosquito Eradicator in comparison to control mortality at different time periods under laboratory conditions 
hydrated Spartan Mosquito Eradicators likely have been more saturated with water vapor than control bug-dorms, thus allowing better survival of mosquitoes.

In the field study, dead mosquitoes were found only once in one treatment tube (2Ae. albopictus and 1 Anopheles quadrimaculatus). Ae. albopictus collected in BG traps did not show any evidence of reduction in abundance in both males and females (Figure 2). Reductions in the numbers collected in the last two replicates were found in both control and treated sites and could be attributed to environmental conditions. Furthermore, very high abun-
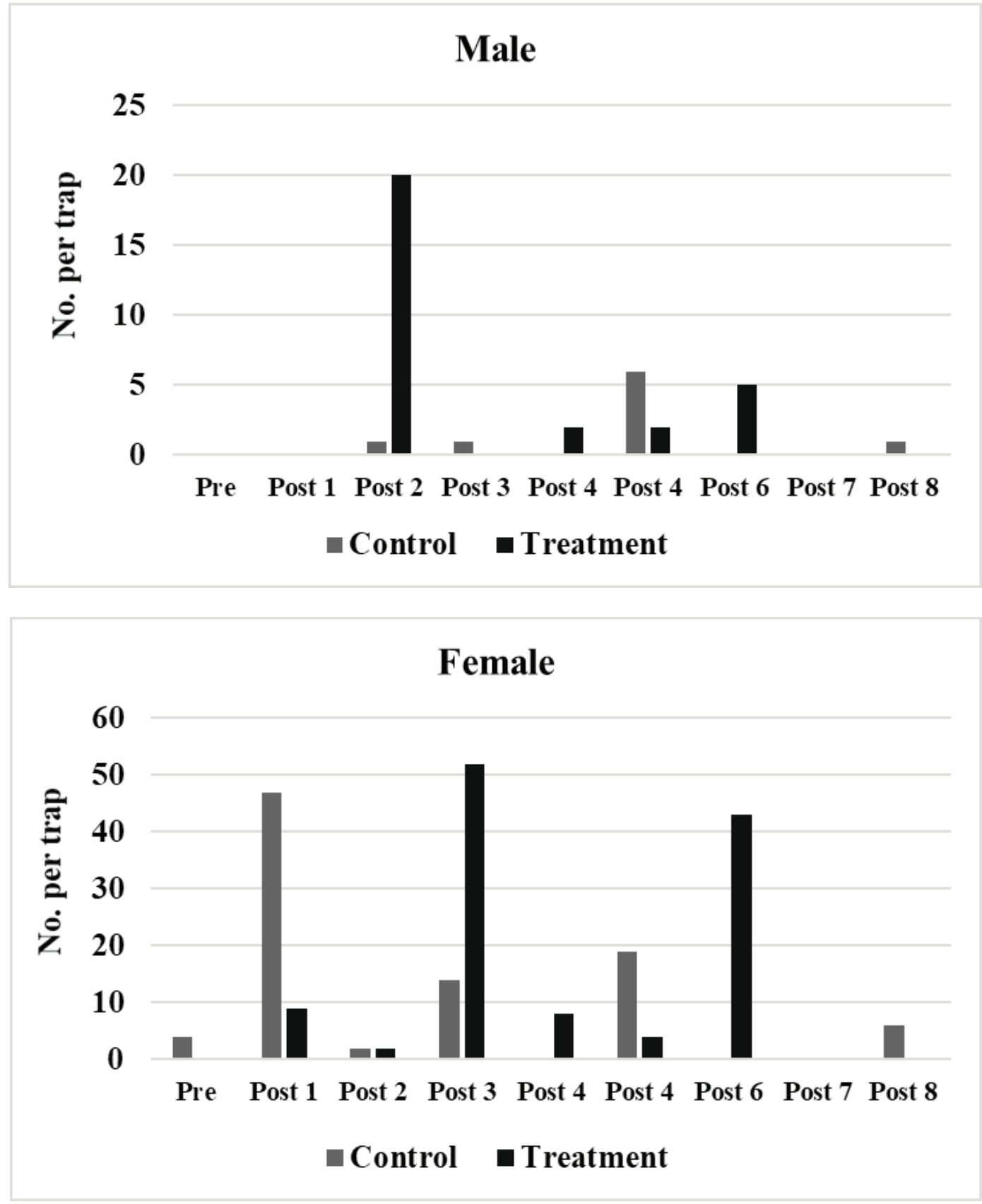

Figure 2. Pre-treatment and post-treatment BioGent Sentinel trap collections of Aedes albopictus males and females during the field study 
dance of Ae. albopictus were casually observed at both sites during each replicate except the last one. Numbers of Ae. albopictus males and females collected by BG traps did not show any significant difference between control and treatment sites (Mann-Whitney $\mathrm{U}=27, \mathrm{p}=0.573$ and $\mathrm{U}=28.5$ and $\mathrm{p}=0.709$, respectively).

Both laboratory and field components of our study show that the Spartan Mosquito Eradicator is not effective in reducing abundance of Ae. albopictus. To compete with many alternative sugar sources in the natural environment the product should be more attractive and the device should be modified so that the mosquitoes can reach the product easily and feed on it. A separate study should be carried out to evaluate the effectiveness of the active ingredient at the concentration ( $1 \%$ sodium chloride) used in the dissolved product.

\section{ACKNOWLEDGEMENTS}

Authors would like to acknowledge $\mathrm{K}$. Blore for rearing mosquitoes, R. Weaver, for the technical help during the study, J. Hainze for reviewing / editing the manuscript, and BioOus, LLC for providing the commercial products for the testing. This is a research report only and does not mean that AMCD endorses any commercial product.

\section{REFERENCES CITED}

Blore K, Beier J, Xue RD. 2018. Impact of three species of aquatic plants on Anopheles quadrimaculatus and its effect on the efficacy of boric acid sugar baits. JAm Mosq Control Assoc. 34: 50-52

Bidlingmayer WI, Hem DG. 1973. Sugar feeding by Florida mosquitoes. Mosq News. 33, 535-538

Deming R, Manrique-Saide P, Medina Barreiro A, Cardena EU, Che-Mendoza A, Jones B, Liebman K, Vizcaino L, Vazquez-Prokopec G, Lenhart A. 2016. Spatial variation of insecticide resistance in the dengue vector $A e-$ des aegypti presents unique vector control challenges. Parasite. Vectors 9: 67

Fiorenzano JM, Koehler PG, Xue RD. 2017. Attractive Toxic Sugar Bait (ATSB) For Control of Mosquitoes and Its Impact on Non-Target Organisms: A Review. Int J Environ Res Public Health. 14: 398. doi: 10.3390/ ijerph14040398

Foster WA. 1995. Mosquito sugar feeding and reproductive energetics. Annu Rev Entomol. 40, 443-474

Lea, AO. 1965. Sugar-baited insecticide residues against mosquitoes. Mosq News. 25, 65-66
Kraemer MU, Sinka ME, Duda KA, Mylne AQ, Shearer FM, Barker CM, Moore CG, Carvalho RG, Coelho GE, Van Bortel W, Hendrickx G, Schaffner F, Elyazar IR, Teng HJ, Brady OJ, Messina JP, Pigott DM, Scott TW, Smith DL, Wint GR, Golding N, Hay SI. 2015. The global distribution of the arbovirus vectors Aedes aegypti and Ae. albopictus. Elife. 4:e08347. doi: 10.7554/ eLife.08347

Kumari R, Kumar K, Chauhan LS. 2011. First dengue virus detection in Aedes albopictus from Delhi, India: its breeding ecology and role in dengue transmission. Trop Med E' International Health.16: 949-954

Maia MF, Tenywa FC, Hannah NH, Kambagha A, Ashura A, Bakari I, Mruah D, Simba A, Bedford A. 2018. Attractive toxic sugar baits for controlling mosquitoes: a qualitative study in Bagamoyo, Tanzania. Malaria Journal. 17:22. doi.org/10.1186/s12936-018-2171-2

McKenzie BA, Wilson AE, Zohdy S. 2019. Aedes albopictus is a competent vector of Zika virus: A meta-analysis. PLoS one. https://doi.org/10.1371/journal.pone.0216794

Monteiro VVS, Navegantes-Lima KC, de Lemos AB, da Silva GL, de Souza Gomes R, Reis JF, Rodrigues Junior LC, da Silva OS, Romão PRT, Monteiro MC. 2019. Aedes-Chikungunya Virus Interaction: Key Role of Vector Midguts Microbiota and Its Saliva in the Host Infection. Front Microbiol.10:492. doi: 10.3389/ fmicb.2019.00492. e Collection 2019

Paupy C, Delatte H, Bagny L, Corbel V, Fontenille D. 2009. Aedes albopictus, an arbovirus vector: from the darkness to the light. Microbes Infect. Des; 11:1177-1185. doi: 10.1016/j.micinf.2009.05.005. Epub 2009

Paupy C, Kassa Kassa F, Caron M, Nkoghé D, Leroy EM. 2012. A chikungunya outbreak associated with the vector Aedes albopictus in remote villages of Gabon. Vector Borne and Zoonotic Diseases.12: 167-169. doi: 10.1089/ vbz.2011.0736

Qualls WA, Muller GC, Revay EE, Allan SA, Arheart KL, Beier JC, Smith ML, Jodi M. Scott JM, Kravchenko VD, Hausmann A, Yefremova ZA, Xue RD. 2014. Evaluation of attractive toxic sugar bait (ATSB)-barrier for control of vector and nuisance mosquitoes and its effect on nontarget organisms in sub-tropical environments in Florida. Acta Trop. 131: 104-110. doi:10.1016/j.actatropica.2013.12.004

Qualls WA, Muller GC, Traore SF, Traore MM, Arheart KL, Doumbia S, Schlein Y, Kravchenko VD, Xue RD, Beier JC. 2015. Indoor use of attractive toxic sugar bait (ATSB) to effectively control malaria vectors in Mali, West Africa. Malaria Journal 14:301. doi.org/10.1186/ s12936-015-0819-8

Sivan A, Shriram AN, Sugunan AP, Anwesh M, Muruganandam N, et al. 2016. Natural transmission of dengue virus serotype 3 by Aedes albopictus (Skuse) during an outbreak in Havelock Island: Entomological characteristics. Acta Tropica. 156:122-129. doi: 10.1016/j.actatropica.2016.01.015

Stewart ZP, Richard M. Oxborough RH, Tungu PK, Matthew J. Kirby MJ, Rowland MW, Seth R. Irish SR. 2013. Indoor Application of Attractive Toxic Sugar Bait (ATSB) in Combination with Mosquito Nets for Control of Pyrethroid-Resistant Mosquitoes. PLoS one 8 (12): e84168

Xue RD, Kline DL, Ali A, Barnard DR. 2006. Application of boric acid baits to plant foliage for adult mosquito control. JAm Mosq Control Assoc. 2006:497-500.

Xue RD, Barnard DR. 2003. Boric acid bait kills adult mosquitoes. JEcon Entomol, 96:1559-1562. 